\title{
Dioxin and diabetes mellitus: an analysis of the combined NIOSH and Ranch Hand data
}

\author{
K Steenland, G Calvert, N Ketchum, J Michalek
}

\begin{abstract}
Objectives-To reanalyze in a similar manner the two principal studies of TCDD (tetrachlorodibenzo- $p$-dioxin) and diabetes in an attempt to reconcile disparate results.
\end{abstract}

Methods-Data from 990 United States Air Force veterans (Ranch Hand) and $\mathbf{1 2 7 5}$ referents were reanalyzed, and a NIOSH population of 267 chemical workers and 227 referents. The Ranch Hand veterans had lower concentrations of lipid adjusted serum TCDD (median 12 parts per trillion (ppt)) than the NIOSH workers (median $75 \mathrm{ppt}$ ) when examined in the late 1980s. An analysis was conducted of the combined data sets, adopting a uniform approach to outcome definition, data analysis, and covariate control.

Results-The combined exposed groups did not differ markedly from the combined non-exposed groups for prevalence of diabetes (odds ratio (OR) $1.17,95 \%$ confidence interval ( $95 \% \mathrm{CI}) 0.92$ to 1.48 ), with no evidence of heterogeneity of exposure effect between studies. Also virtually no difference was found between combined exposed and non-exposed groups in mean fasting serum glucose (difference in log serum glucose $0.002,95 \%$ CI -0.006 to 0.010 ), and there was little evidence in either study of a dose-response trend for fasting serum glucose. An increasing trend was found $(p=0.0001)$ in prevalence of diabetes with increased TCDD (at the time of examination or at time of last exposure) among the Ranch Hand population, with excess risk largely confined to the highest $8 \%$ of the exposed group $(>78$ ppt serum TCDD), which had an OR of $3.21(95 \%$ CI 1.81 to 5.72$)$ versus those with $<10$ ppt TCDD. However, no such positive dose-response was found in the NIOSH population.

National Institute for Occupational Safety and Health (NIOSH), Cincinnati, Ohio, USA K Steenland G Calvert

Air Force Research Laboratory, Brooks Air Force Base, Texas, USA

N Ketchum

J Michalek

Correspondence to:

Dr K Steenland

nsteenland@cdc.gov

Accepted 7 June 2001
Conclusions-There was little overall evidence that the exposed workers were at higher risk than the non-exposed workers of diabetes or abnormal fasting glucose. However, the Ranch Hand subjects showed a positive dose-response for diabetes, whereas the more highly exposed NIOSH subjects did not. The reason for the difference in diabetes doseresponse trends between the two studies is unknown.

(Occup Environ Med 2001;58:641-648)

Keywords: dioxin; diabetes; TCDD
2,3,7,8-Tetrachlorodibenzo- $p$-dioxin (TCDD) is the most potent congener of a class of chemicals known as dioxins. There has been some concern about the possible relation between TCDD and diabetes, due to animal data indicating that TCDD affects glucose transport ${ }^{1}$ and reports about increased morbidity from diabetes or increased serum glucose in humans exposed to TCDD. The two principal reports about TCDD and diabetes in humans have been published by Henriksen et $a l^{2}$ and Calvert et $a^{\beta}$; they provide the data for the current analysis and are discussed in detail below. A third report ${ }^{4}$ is of limited interest because its assessment of diabetes was limited to hospital admissions. A fourth report ${ }^{5}$ is limited to serum glucose; these authors found a positive trend of increased fasting glucose with increasing current exposure to TCDD among 138 men occupationally exposed for at least 35 years, after controlling for age and current body mass index. Finally, a recent study ${ }^{6}$ reported on 69 people exposed near a plant which produced Agent Orange; their serum TCDD concentrations ranged from 2 to 94 parts per trillion (ppt). All subjects had a normal glucose tolerance test. However, the seven subjects with TCDD above $15 \mathrm{ppt}$ had markedly higher concentrations of plasma insulin at fasting and after the glucose load than those below $15 \mathrm{ppt}$. High insulin with normal glucose suggests insulin resistance and may be a precursor to impaired glucose tolerance and diabetes.

There have also been reports with mixed results about mortality from diabetes among workers exposed to dioxins..$^{7-9}$ However, mortality is a much less sensitive end point than morbidity and typically mortality studies are unable to control for several important risk factors for diabetes - for example, obesity and family history.

The two principal published studies on morbidity from diabetes mellitus (United States Air Force veterans and United States chemical workers) are summarised in table 1. Further details on TCDD concentrations in both populations can be found in table 2 .

The first study ${ }^{2}$ concerned 989 United States Air Force veterans of Operation Ranch Hand, who had sprayed agent orange contaminated with TCDD in Vietnam in the 1960s and 1970s, and a non-exposed comparison group of other Air Force veterans $(n=1276)$. A cross sectional study of prevalent diabetes relative to serum concentrations of TCDD was conducted, with prevalence of diabetes ascertained to the end of June 1995 and serum dioxin ascertained in the late 1980s or the early 1990s. The long half life of TCDD (about 7-9 years) 


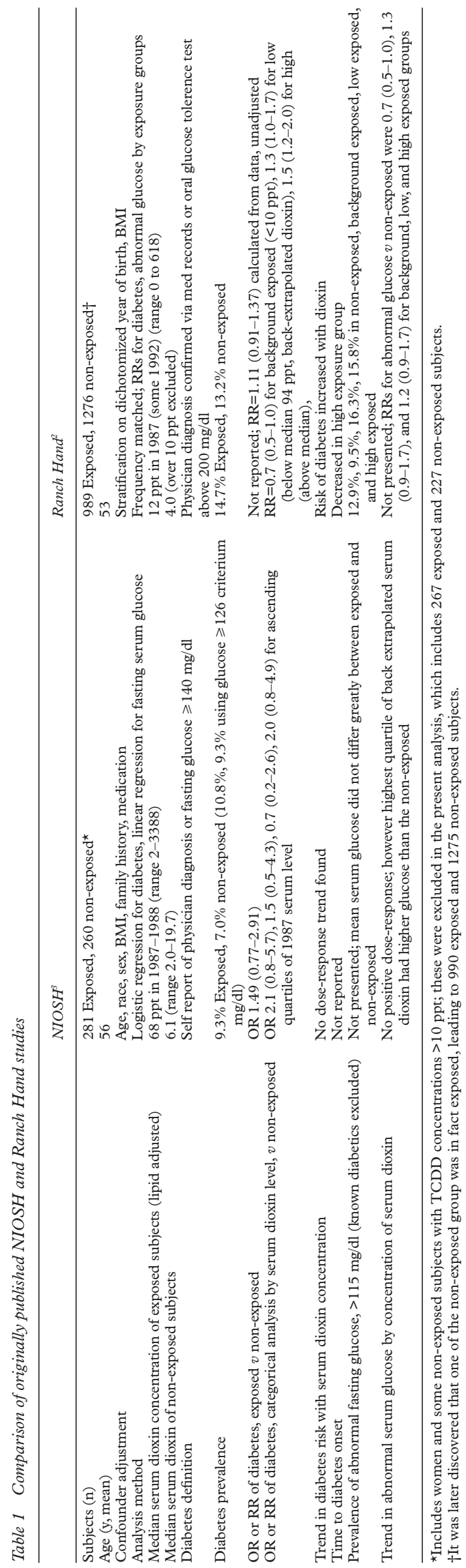

allowed the use of serum TCDD in the 1980s as a measure of dose in the 1960s and 1970s. The median lipid adjusted serum TCDD concentration of exposed subjects was $12 \mathrm{ppt}$ in 1987 (range 0-618 ppt). This study found no difference in prevalence of diabetes between the exposed and non-exposed subjects, but did find an increasing risk of diabetes with increased serum TCDD among the exposed group. Those with the highest exposure (median 46, range 18-618 ppt) had a relative risk (RR) of 1.5 (95\% confidence interval ( $95 \%$ CI) 1.2 to 2.0 ) versus the non-exposed group. Findings were similar for abnormal fasting glucose (known diabetic subjects excluded), although for this outcome the positive trend among the exposed subjects was only slight, and the group with highest exposure had an RR of only 1.2 (95\% CI 0.9 to 1.7 ) versus the non-exposed group. Among non-diabetic subjests, the risk of abnormally high insulin increased with TCDD concentration. This study also found decreased time to diabetes among the group with highest serum TCDD.

The second principal study ${ }^{3}$ on morbidity from diabetes concerned 281 workers who made 2,4,5-trichlorophenol, agent orange, and other TCDD contaminated products at two plants from the 1950s until the early 1970s, and a non-exposed comparison group of 260 community residents. ${ }^{3}$ A cross sectional study was conducted by the National Institute for Occupational Safety and Health (NIOSH) in the late 1980 s, similar in design to the Air Force study. Serum TCDD and prevalence of diabetes were ascertained in 1987-8. The median (range) lipid adjusted serum TCDD concentration among exposed workers was 68 (2-3888) ppt. This study found an odds ratio (OR) of 1.49 (95\% CI 0.77 to 2.91 ) for the exposed versus the non-exposed subjects for prevalence of diabetes. No trend was found between TCDD concentration and fasting glucose, although the quartile of exposed subjects with the highest back extrapolated TCDD concentration ( $>1860 \mathrm{ppt}$ at time of last exposure) did have higher serum glucose than the non-exposed subjects $(5.45 \mathrm{nmol} v 5.21$ $\mathrm{nmol})$. Time to diabetes was not analyzed.

The two studies treated potential confounders differently, had somewhat different definitions of outcomes, and used different approaches to data analysis. This made comparison of results somewhat difficult. To overcome these difficulties, we have conducted an analysis of the combined data from the two studies. A recent review by the Institute of Medicine noted differences between the two studies and called for this kind of analysis. ${ }^{10}$

\section{Materials and methods}

\section{OUTCOME DEFINITIONS}

Diabetes was defined as either reporting diabetes diagnosed by a physician, or having an oral glucose tolerance test (OGTT) $>200$ $\mathrm{mg} / \mathrm{dl}$ (Ranch Hand), or having a fasting serum glucose of $126 \mathrm{mg} / \mathrm{dl}$ or more (NIOSH). The NIOSH did not conduct the OGTT test; however, a fasting glucose of $126 \mathrm{mg} / \mathrm{dl}$ is about 
Table 2 Serum TCDD concentrations (ppt) of exposed subjects in the current analysis

\begin{tabular}{|c|c|c|c|c|c|}
\hline Study & Mean (SD) & Median & Range & $\begin{array}{l}>10 p p t \\
(n(\%))\end{array}$ & $\begin{array}{l}\text { Back extrapolated } \\
\text { median (range) } \neq\end{array}$ \\
\hline NIOSH $(n=259)^{\star}$ & $229(446)$ & 75 & $2-3388$ & $226(87)$ & $584(35-19744)$ \\
\hline Ranch Hand $(n=990) \dagger$ & $27(45)$ & 12 & $0-618 \Omega$ & $567(57)$ & $94(27-3290)$ \\
\hline Total $(n=1248)$ & $69(223)$ & 16 & $0-3388$ & $793(63)$ & $138(27-19744)$ \\
\hline
\end{tabular}

${ }^{\star}$ Excludes women and eight men who had missing TCDD concentrations.

tOne non-exposed subject in the original analysis was found to actually have been exposed, leading to 990 exposed in the present analysis $v 989$ in the original publication (Henriksen et al $1997^{2}$ ). $\ddagger$ Calculated only for those with $>10$ ppt.

$§$ The limit of detection varied by sample volume of blood available; the median was 3 ppt.

equivalent to a OGTT $>200 \mathrm{mg} / \mathrm{dl}$, permitting an equivalent analysis of this outcome across both studies. ${ }^{11}$

Diabetes was self reported in the NIOSH data, whereas in the Ranch Hand study all self reported diagnosed diabetes (and diagnosis dates) were confirmed by medical records. We have ignored this distinction and grouped self reported and confirmed diabetes across studies.

Fasting glucose was ascertained similarly for both studies.

POPULATION DEFINITION

The original NIOSH study population consisted of 541 subjects (281 exposed, 260 non-exposed referents). To conform to the Ranch Hand study, the 31 women in the NIOSH study were excluded. Also, 16 male non-exposed subjects in the NIOSH study with TCDD $>10$ ppt (mean 14 ppt, range 10-19) were further eliminated, also to conform to the Ranch Hand study, in which the non-exposed referents were required to have a TCDD $\leqslant 10$ ppt. This left a population of 494 (267 exposed, 227 non-exposed). For analyses by TCDD concentration, an additional eight exposed subjects with missing TCDD values in the NIOSH study were excluded. Only 99 of the 260 original non-exposed subjects in the NIOSH study had their TCDD measured, due to cost considerations and expectation that the background concentrations expected in a nonexposed population would be homogenous and low. All non-exposed subjects in the NIOSH study for whom TCDD was not measured were assigned a TCDD concentration of 6.1 ppt, which was the median in the 99 original non-exposed subjects whose TCDD was measured (range 2.0-19.7 ppt). Given that 16 of $99 \mathrm{NIOSH}$ non-exposed subjects who were measured for serum TCDD had concentrations above $10 \mathrm{ppt}$ it is likely that some NIOSH non-exposed subjects who were not measured and who were assigned the $6.1 \mathrm{ppt}$ concentration would be expected to have had concentrations higher than $6.1 \mathrm{ppt}$, thereby distorting the true dose-response relations. However, this effect would not be expected to be large; the 16 subjects excluded were not highly exposed; their median concentration was $12 \mathrm{ppt}$, with a range of 11-20 ppt.

In the present analysis we have retained the original number of Ranch Hand subjects, except that one subject originally classified as non-exposed was found to have been exposed, so that the exposed group in the present study numbered 990, and the non-exposed group numbered 1275 .
This led to a combined population of 2759 exposed and non-exposed men for the analysis of prevalence of diabetes (494 from NIOSH (23\%), 2265 from Ranch Hand (77\%)). Of these 2759, 1257 (45\%) were exposed (990 from Ranch Hand, 267 from NIOSH). Of the 2759 total population, $366(13 \%)$ were diabetic (315 from Ranch Hand, 14\% prevalence, 51 from NIOSH, $10 \%$ prevalence). All diabetic subjects had been diagnosed after exposure; $29 \%$ were diagnosed through high glucose at the time of examination.

Ranch Hand fasting serum glucose was based on a 1992 examination, which included data on 2125 subjects. For the analysis of fasting serum glucose, diabetic subjects diagnosed before the examination were eliminated from both data sets (306 from Ranch Hand and 32 from NIOSH). This left a population with fasting glucose values of 2309 subjects.

For the time to diabetes analysis, we restricted the data set to those who were exposed. Time was defined as time from last exposure to diagnosis of diabetes for diabetic subjects. For the non-diabetic group, time was defined as the time from last exposure to end of follow up. This led to a data set of 1254 people, 264 from NIOSH (21\%), and 990 from Ranch Hand $(79 \%)$, of whom there were 175 with diabetes (prevalence of 14\%), 28 from NIOSH (11\% prevalence) and 147 from Ranch Hand (15\% prevalence). Thirty one per cent of the exposed diabetic subjects were diagnosed at the time of the examination.

\section{EXPOSURE VARIABLES}

Exposure variables analyzed included a dichotomous variable for exposure (exposed $v$ non-exposed), as well a continuous variable which was either lipid adjusted TCDD at the time of the examination, or lipid adjusted TCDD back extrapolated to time of last occupational exposure using the estimated half life of TCDD. Back extrapolation was done by assuming a first order elimination model:

$$
\mathrm{TCDD}_{\mathrm{t} 1}=\mathrm{TCDD}_{\mathrm{to}} \exp \left(-\lambda \lambda^{\star} \Delta \mathrm{t}\right)
$$

where $t_{1}$ is serum TCDD at the time of last exposure, $t_{o}$ is serum TCDD at the time of the examination, $\Delta t$ is the time between last exposure and the time of the examination, and $\lambda$ is 0.0797 based on assuming an 8.7 year half life. Serum concentrations were measured by the same laboratory for both studies, with the same methods. ${ }^{12}$ Exposure-response analyses by back extrapolated TCDD were conducted only among exposed subjects who had TCDD $>10$ ppt at the time of the examination, which excluded all referents from both studies, as well as the "background group" from Ranch Hand, and $33(13 \%)$ of the exposed workers from the NIOSH study. The rationale for these exclusions was that a meaningful back extrapolated value cannot be calculated for subjects who have returned to background concentrations of TCDD, as it cannot be stated how long they have been at the background concentration. Analyses by back extrapolated TCDD were restricted to 793 people, 226 from NIOSH (29\%), 567 from Ranch Hand (71\%). 
COVARIATE DEFINITION AND INCLUSION IN MODELS

Covariates considered were smoking history, alcohol history, family history of diabetes (first degree relative), body mass index at the time of the examination (by quartiles), year of birth (continuous), race (white, other), current taking of medications possibly contributing to diabetes or increased serum glucose (thyroxine, glucocorticoids, diuretics, phenytoin, $\beta$-blockers, nicotinic acid; $11 \%$ of the combined population were taking such medication, $10 \%$ in Ranch Hand, $18 \%$ in NIOSH), and education (high school or less, some post high school, college graduate). Smoking and alcohol history were not significant predictors of any outcome and were dropped from all models. The other variables were generally important predictors for the full data set and were retained in all models. For time to diabetes analyses, age at last exposure was added to the model as well as birth year.

The non-exposed population in the Ranch Hand study had been chosen through frequency matching on age, race, and military occupation. In our analysis age and race were controlled by inclusion of covariates for birth year and race in the model; military occupation was not included in the model because it had no analogue in the NIOSH population. Instead we included education as a measure of socioeconomic class, which would correlate with military occupation.

The inclusion of current medication in models is somewhat debatable. Many subjects were taking antihypertensive drugs, which increased fasting glucose, and therefore potentially are an important confounder for analyses of that outcome, if taking hypertensive drugs were also associated with exposure. Antihypertensive drugs could potentially confound analyses of diabetes as well (21\% of diabetic subjects were taking medication, compared with $10 \%$ of non-diabetic subjects). However, medication may also be a corollary of disease, as many diabetic subjects are hypertensive, in which case hypertensive medication should not be treated as a confounder. In practice the variable for medication had little effect on the estimates of exposure effect for any outcome. However, we did include the variable for medication in the models for serum glucose, where its potential confounding role is most clear.

As already noted, a variable for study (Ranch Hand or NIOSH) was included in all models; this variable was an important predictor of all outcomes.

\section{ANALYTICAL APPROACH}

Analyses were conducted for either dichotomous exposure (exposed $v$ non-exposed), or by concentration of serum TCDD. Prevalence of diabetes was analyzed by logistic regression (SAS PROC LOGIST ${ }^{13}$ ), fasting glucose (log serum glucose, nmol/l) was analyzed by linear regression (SAS PROC REG), and time from last exposure to diagnosis of diabetes was analyzed by Cox's regression (SAS PROC PHREG). Supplementary logistic regression analyses also considered abnormal serum glucose $(>115 \mathrm{mg} / \mathrm{dl})$ as a dichotomous outcome. Analyses of time to diabetes were somewhat limited by the fact that $31 \%$ of the exposed diabetic subjects were ascertained by high fasting glucose at time of examination, and hence their time to diabetes was likely to be underestimated compared with those with a diagnosis by a doctor.

Both separate analyses of each study and combined analyses were conducted for all outcomes. Results of combined analyses are not presented if results differed markedly between studies, as judged by inspection of effect measures and evaluation of study-exposure interaction. TCDD (at the time of the examination) and back extrapolated TCDD were analyzed both as continuous variables (logged and unlogged) and as categorical variables. For the logged variable, 1.0 was added to the TCDD concentration if the TCDD concentration was 0 , to avoid taking the $\log$ of 0 . Log transformation tends to diminish the influence of those with extremely high TCDD concentrations on the regression; TCDD concentrations are log normally distributed with a few very high values. Categorical analyses were done by dividing the exposed subjects who had TCDD concentrations (at the examination) above 10 ppt into quartiles, and considering the group with TCDD $\leqslant 10 \mathrm{ppt}$ as the referent. Those above $10 \mathrm{ppt}$ represented $63 \%$ of the exposed population, and $29 \%$ of the combined exposed and non-exposed population. Those with TCDD $\leqslant 10$ were the non-exposed population from both studies, the "background" exposed group from Ranch Hand, and the 33 NIOSH exposed subjects with TCDD <10 ppt. Categorical analyses with back extrapolated TCDD were restricted entirely to those with TCDD above $10 \mathrm{ppt}$ at the time of the examination, and were done by dividing that population into quartiles, and considering the lowest group as referent.

\section{Results}

EXPOSURE CONCENTRATIONS

Exposure concentrations in terms of serum TCDD (ppt) for the population studied here are given in table 2 . The NIOSH population had considerably higher concentrations than the Ranch Hand population.

PREVALENCE OF DIABETES

The OR for exposed versus non-exposed subjects (not shown) was 1.17 (95\% CI 0.92 to 1.48). The ORs were virtually the same for each study $(1.18,95 \%$ CI 0.91 to 1.52 for Ranch Hand, 1.22, 95\% CI 0.65 to 2.29 for NIOSH).

Results for dose-response analyses by TCDD at examination are shown in table 3 . The dose-response for the two study populations were markedly different. The doseresponse for TCDD was considerably stronger among the Ranch Hand population, although this population overall had lower TCDD concentrations. As a consequence, results combining the two studies are not presented. The positive trend for untransformed TCDD in the NIOSH cohort was due to the fact that 
Table 3 Results for prevalence of diabetes by current TCDD concentration (ppt at time of examination), logistic regression

\begin{tabular}{llll}
\hline Study & $\begin{array}{l}\text { Coefficient for TCDD } \\
(95 \% \mathrm{CI})^{\star}\end{array}$ & $\begin{array}{l}\text { Coefficient for } \log \text { TCDD } \\
(95 \% \mathrm{CI})^{\star}\end{array}$ & $\begin{array}{l}\text { OR (95\% CI) by quartile TCDD }>10 \text { ppt } v<10 \\
\text { pptt }\end{array}$ \\
\hline Ranch Hand & $0.0065(0.0032$ to 0.0099$)$ & $0.2401(0.1139$ to 0.3663$)$ & $\begin{array}{l}1.39(0.91 \text { to } 2.14), 1.33(0.85 \text { to } 2.10), 1.11 \\
(0.67 \text { to } 1.88), 3.21(1.81 \text { to } 5.72)\end{array}$ \\
NIOSH & $0.0008(0.0002$ to 0.0015$)$ & $0.0263(-0.1428$ to 0.1954$)$ & $\begin{array}{l}0.67(0.07 \text { to } 6.24), 1.73(0.57 \text { to } 5.26), 0.88 \\
(0.28 \text { to } 2.78), 0.84(0.40 \text { to } 1.77)\end{array}$ \\
\hline
\end{tabular}

*A test for heterogeneity of exposure effect between studies gave $\mathrm{p}=0.0009$ for TCDD, and $\mathrm{p}=0.04$ for $\log$ TCDD. †Quartiles are $10-17,17-30,30-78, \geqslant 78$, based on the combined data; the referent is $<10 \mathrm{ppt}$.

the four men with the highest TCDD values in the NIOSH data were diabetic; log transformation of TCDD lessened the influence of these very high values and eliminated most of the positive effect in the NIOSH cohort. Furthermore, categorical analyses indicated no positive trend in the NIOSH cohort.

Dose-response analyses for back extrapolated TCDD, assessed only for those with TCDD $>10$ ppt at the time of the examination, are shown in table 4 . These are qualitatively similar to the results for TCDD at the time of the examination; positive results are largely restricted to the Ranch Hand cohort.

To further explore the effect for TCDD in the Ranch Hand population, we considered the possibility of effect modification by age or body mass index. After dividing the Ranch Hand cohort into high and low body mass index (cut off point at the median 27.3), and high and low age (cut off point at the median 49 years), we found no marked effect modification by age or body mass index. An analogous analysis of the $\mathrm{NIOSH}$ data likewise found little evidence of effect modification.

We also considered a model for the Ranch Hand population in which the non-exposed subjects only were used as the comparison, and a separate category was created for the exposed subjects with TCDD $<10 \mathrm{ppt}$ (at the time of the examination). The ORs (95\% CIs) for Ranch Hand exposed versus the non-exposed were 0.83 ( 0.56 to 1.21$), 1.33$ (0.86 to 2.06 ), 1.29 (0.82 to 2.04$), 1.08$ (0.64 to 1.83 ), and 3.11 (1.74 to 5.55), for exposed $<10 \mathrm{ppt}$, exposed 10-17 ppt, exposed 17-30 ppt, exposed $30-78 \mathrm{ppt}$, and exposed $\geqslant 78 \mathrm{ppt}$, confirming that the increased risk was found only in the highest TCDD category. This category $(>78 \mathrm{ppt})$ represents the top $8 \%$ of exposure in the Ranch Hand cohort $(n=70)$.

FASTING SERUM GLUCOSE

We found little evidence of an increase in log serum glucose for the exposed versus nonexposed subjects. The difference of log serum glucose between exposed and non-exposed was 0.002 (95\% CI -0.006 to 0.010$)$. There was little evidence of effect modification by study.

Table 4 presents results for dose-response trends between TCDD and serum glucose. The combined studies showed a positive trend of increasing log serum glucose with increasing TCDD, with little heterogeneity between the two separate studies. However, quartile analyses did not suggest any consistent trend, for either study or for the combined data. Furthermore, the positive trend with TCDD in the combined data was entirely dependent on three observations (out of 2309) with the highest influence (measured by the d-beta statistic from PROC REG); these were three NIOSH subjects with very high serum glucose concentrations (above $180 \mathrm{mg} / \mathrm{dl}$ or $10 \mathrm{mmol} / \mathrm{l}$ ). The positive linear trend with TCDD disappeared (in fact became slightly negative) when these three men were excluded. Calvert et $a \beta^{\beta}$ had noted the influence of these three subjects in the earlier publication of these data. A weak positive trend was noted with $\log$ TCDD in both studies separately and in the combined data; again in the combined data this trend changed from positive to negative with the exclusion of the three influential values. Analyses with back extrapolated TCDD (not shown) had a similar pattern as TCDD at the time of the examination.

We also considered a dichotomised variable, abnormal (>115 mg/dl) serum (fasting) glucose, as the outcome variable, through logistic regression. In the combined data set there were 96 subjects with abnormal serum glucose $(4 \%$ of the subjects, 29 from NIOSH, and 67 from Ranch Hand). There was no effect of exposure on the risk of abnormal serum glucose (OR 0.92 for exposed subjects $v$ non-exposed, $95 \%$ CI 0.55 to 1.92), with no evidence of heterogeneity between studies. Furthermore there were no strong trends between TCDD, $\log$ TCDD, back extrapolated TCDD, or the log of back extrapolated TCDD and abnormal serum glucose; nor was any evidence of

Table 4 Results for diabetes prevalence by back extrapolated TCDD (to end of exposure), logistic regression, restricted to exposed subjects with $>10$ ppt TCDD at time of examination

\begin{tabular}{llll}
\hline Study & $\begin{array}{l}\text { Coefficient for TCDD } \\
(95 \% \mathrm{CI})^{\star}\end{array}$ & $\begin{array}{l}\text { Coefficient for log TCDD } \\
(95 \% \mathrm{CI})^{\star}\end{array}$ & $\begin{array}{l}\text { OR (95\% CI) by quartile TCDD >10 ppt, } \\
\text { referent }<10 \text { ppt } \dagger\end{array}$ \\
\hline Ranch Hand & $0.0013(0.0005$ to 0.0020$)$ & $0.3174(0.0575$ to 0.5773$)$ & $\begin{array}{l}1.02(0.57 \text { to } 1.85), 1.60(0.83 \text { to } 3.06), 2.30 \\
(1.07 \text { to } 4.94)\end{array}$ \\
NIOSH & $0.0002(0.0000$ to 0.0003$)$ & $0.1796(-0.2044$ to 0.5635$)$ & NA
\end{tabular}

* The test for heterogeneity of exposure effect between studies gave $\mathrm{p}=0.01$ for untransformed TCDD, and $\mathrm{p}=0.41$ for $\log$ transformed TCDD.

tQuartiles are 10-64, 64-140, 140-376, $\geqslant 376 \mathrm{ppt}$, common cut off points based on the combined data.

$\$ Q$ uartile ORs could not be estimated with common cut off points because there were no NIOSH cases in the 2nd quartile. Collapsing the 2nd and 3rd quartiles, the ORs for the NIOSH data for quartiles $2 / 3 v 1$ is 0.76 and for quartile $4 v 1$ is 0.65 . With NIOSH specific cut off points $(10-243,243-584,584-1515, \geqslant 1515)$, ORs by quartiles were $0.94,1.06,0.75$ respectively for the upper three quartile $v$ the first. 
Table 5 Results for log serum glucose (fasting glucose, mmol/l), linear regression

\begin{tabular}{|c|c|c|c|}
\hline Study & Coefficient for TCDD $(95 \% C I)^{\star}$ & $\begin{array}{l}\text { Coefficient for } \log T C D D \\
(95 \% C I)^{\star}\end{array}$ & $\begin{array}{l}\text { Change in log serum glucose by quartile of TCDD }>10 \text { ppt } \\
(95 \% \mathrm{CI}) \text {, referent }<=10 \mathrm{ppt}+\end{array}$ \\
\hline Ranch Hand & $0.00006(-0.00009$ to 0.00021$)$ & $0.0016(-0.0025$ to 0.0057$)$ & $\begin{array}{l}-0.001(-0.016 \text { to } 0.016),-0.001(-0.017 \text { to } 0.014) \\
-0.011(-0.028 \text { to } 0.004), 0.014(-0.024 \text { to } 0.038)\end{array}$ \\
\hline $\mathrm{NIOSH}$ & $0.00004(-0.00001$ to 0.00009$)$ & $0.0033(-0.0047$ to 0.0113$)$ & $\begin{array}{l}-0.016(-0.077 \text { to } 0.045),-0.017(-0.065 \text { to } 0.031) \\
-0.033(0.078 \text { to } 0.012), 0.014(-0.017 \text { to } 0.045)\end{array}$ \\
\hline Combined & $0.00004(0.00001$ to 0.00008$)$ & $0.0025(-0.0010$ to 0.0060$)$ & $\begin{array}{l}-0.004(-0.019 \text { to } 0.013),-0.005(-0.016 \text { to } 0.011) \\
-0.017(-0.033 \text { to } 0.007), 0.018(0.001 \text { to } 0.035)\end{array}$ \\
\hline$R^{2}$ combined model & 0.09 & 0.09 & 0.09 \\
\hline $\begin{array}{l}\text { Combined without the three most } \\
\text { influential observations }\end{array}$ & $-0.00001(-0.00005$ to 0.00003$)$ & $-0.0004(-0.0039$ to 0.0032$)$ & $\begin{array}{l}-0.003(-0.018 \text { to } 0.013),-0.005(-0.020 \text { to } 0.011) \\
-0.017(-0.033 \text { to }-0.001), 0.004(-0.012 \text { to } 0.020)\end{array}$ \\
\hline
\end{tabular}

${ }^{\star}$ A test for heterogeneity of exposure effect between studies gave $\mathrm{p}=0.90$ for TCDD and $\mathrm{p}=0.24$ for log TCDD, when data included three most influential observations.

†Quartiles for each study and for combined data are 10-17, 17-30, 30-78, $\geqslant 78$ ppt for those $>10$ ppt.

heterogeneity between studies found for any of these exposure metrics. Categorical analyses of the combined data by each quartile of exposure to TCDD for those with $>10 \mathrm{ppt}$ TCDD at the time of the examination versus a comparison group of the non-exposed and exposed subjects with TCDD $<10 \mathrm{ppt}$, resulted in ORs of 1.33 , $0.74,0.53$, and 0.98 .

TIME TO DIABETES

Results for time to diabetes, restricted to the exposed population, were similar to results for prevalence of diabetes. These analyses were restricted to the exposed subjects.

Results are shown in table 5 for TCDD at the time of the examination. Again, these differed between studies and we do not present combined results. There was a strong positive trend in shorter time to diabetes among the more highly exposed Ranch Hand subjects. The trend in the NIOSH study was also positive but considerably weaker based on the continuous variable for TCDD concentration, but became negative when using the log of TCDD. Categorical analysis of the NIOSH data did not show an increasing trend, again suggesting that a few outliers were driving the trend test with untransformed continuous TCDD.

Results for time to diabetes with back extrapolated TCDD (analyzed only among those with $>10 \mathrm{ppt}$ at the time of the examination) were similar to the results in table 5, and are not presented. Again, positive trends in time to diabetes were found only for Ranch Hand subjects.

\section{Discussion}

Overall, there was little evidence of an effect of TCDD on prevalence of diabetes in either study population or in a combined analysis when we compared the exposed to the non-exposed subjects. However, when we conducted dose-response analyses which looked for a trend of increased diabetes with increased TCDD concentrations, we found different results for each study population. There was little evidence of a trend between TCDD concentration and prevalence of diabetes in the $\mathrm{NIOSH}$ subjects, although these subjects had higher concentrations than the Ranch Hand subjects. On the other hand, there was evidence of increased prevalence of diabetes with increasing TCDD concentrations in the Ranch Hand subjects. This effect was concentrated in those with the highest TCDD concentrations in the Ranch Hand subjects (OR 3.21 for those with $>78$ ppt serum TCDD at the time of the 1992 examination (top $8 \%$ of the exposed group), compared with those with TCDD $<10$ ppt). It is not clear why the equivalent group (>78 ppt) in the NIOSH analysis did not show any evidence of increased risk (OR 0.84). Due to this heterogeneity of findings, it is impossible to draw any firm conclusions about the relation between concentration of exposure to TCDD and diabetes from these results

We can only speculate why the two studies differ in dose-response for diabetes. The two studies differed somewhat for ascertainment of diabetes, other organic chemical exposures, and patterns of exposure to TCDD. We attempted to use a common definition of diabetes and a common analytical approach to both data sets. However, diabetes was self reported in the NIOSH study and confirmed by reviewing medical records after self report in the Ranch Hand study. Also, Ranch Hand and comparison(non-exposed) veterans received glucose testing in 1992 and at previous examinations in 1982, 1985, and 1987. All veterans with increased glucose concentrations were telephoned and advised to see their doctor,

Table 6 Results for time to diabetes by current TCDD (ppt at time of examination), Cox's regression, exposed subjects only

\begin{tabular}{|c|c|c|c|}
\hline Study & $\begin{array}{l}\text { Coefficient for TCDD } \\
(95 \% C I)^{\star}\end{array}$ & $\begin{array}{l}\text { Coefficient for } \log T C D D \\
(95 \% C I)^{\star}\end{array}$ & $\begin{array}{l}\text { Rate ratio }(95 \% \text { CI) by quartile of TCDD } \\
>10 \text { ppt, referent }<10 \text { ppt } t\end{array}$ \\
\hline Ranch Hand & $0.0060(0.0039$ to 0.0082$)$ & $0.1975(0.0299$ to 0.3650$)$ & $\begin{array}{l}1.60(0.99 \text { to } 2.58), 1.76 \text { (1.06 to } 2.93) \text {, } \\
1.57(0.89 \text { to } 2.79), 4.48 \text { (2.48 to } 8.09)\end{array}$ \\
\hline NIOSH & $0.0008(0.0001$ to 0.0016$)$ & $-0.0308(-0.3183$ to 0.2567$)$ & $\begin{array}{l}0.27(0.03 \text { to } 2.70), 0.90(0.25 \text { to } 3.29) \\
0.51(0.13 \text { ot } 2.04), 0.42(0.12 \text { to } 1.49)\end{array}$ \\
\hline
\end{tabular}

${ }^{\star} \mathrm{A}$ test for heterogeneity between exposure and study gave $\mathrm{p}=0.0001$ for TCDD and $\mathrm{p}=0.005$ for $\log \mathrm{TCDD}$.

tQuartiles are $10-17,17-30,30-78,78+$, based on the combined data; the referent is $<10 \mathrm{ppt}$. 
which led to additional diagnosed cases (examiners and study staff conducting the telephone follow up were blinded to the exposure and dioxin concentrations of the veterans). Corresponding repeated testing and follow up did not occur in the NIOSH study. None the less, it would seem unlikely that underascertainment of diabetes in the NIOSH subjects would be substantial, or that it could lead to failure to find a true positive dose-response trend.

It is possible that some Ranch Hand personnel were exposed to insecticides (Malathion and DDT) as well as herbicides, and these insecticides might have caused diabetes, preferentially among those with higher TCDD concentrations. However, we know of no publications to support an association between these insecticides and diabetes. Also, insecticide spraying accounted for only 20 of 556 (3.6\%) sorties by Ranch Hand personnel during the peak spraying period in July $1967 .{ }^{14}$ Of the herbicides sprayed in Vietnam, agent orange $(2,4-\mathrm{D}$ and 2,4,5-T) represented $62.9 \%$, agent white $(2,4-\mathrm{D}$ and picloram) represented $29.3 \%$, and agent blue (cacodylic acid or dimethyl arsinic acid) represented $6.3 \% .^{15}$ There is some evidence in prevalence studies that inorganic arsenic in drinking water is associated with diabetes. ${ }^{16-18} \mathrm{~A}$ mechanism has been proposed by which inorganic arsenic may inhibit glucose uptake, based on in vitro experiments with rat cells. ${ }^{16}$ Cacodylic acid is the primary metabolite of inorganic arsenic, produced through methylation in the liver. ${ }^{19}$ The methyl derivatives are thought in general to be less toxic than their parent inorganic compounds (Agency for Toxic Substances and Disease Registry, 1998). ${ }^{19}$ The proposed mechanism (through inorganic arsenic) and the lesser toxicity of methylated arsenic would make it less likely that agent blue (methylated arsenic) could cause diabetes, but this possibility cannot be excluded.

Conversely, it is theoretically possible that $\mathrm{NIOSH}$ chemical workers were exposed to other chemicals which were protective against the toxic effects of TCDD. Others have noted that the effects of other dioxin congeners and furans could be either additive or antagonistic. ${ }^{20}$ However, we know of no well established instances in the epidemiological literature where one occupational chemical exposure protected against a toxic effect of another (for any outcome).

Regarding patterns of exposure, Ranch Hand workers were exposed for a single short period ( 1 year on the average). The NIOSH workers were exposed from 1 day to 18 years, with a mean of 3 years (SD 4.5 years, median 1 year). It is not clear why this different pattern would affect dose-response trends. For time since exposure, Ranch Hand personnel were last exposed on the average in 1968 SD 2.0 years), whereas $\mathrm{NIOSH}$ subjects were last exposed on the average in 1964 (SD 6.3 years), and some were last exposed much earlier. It is possible that there is a time window in which only recent exposure results in diabetes; however, restriction of the NIOSH subjects to those with more recent exposure (1964 or later) did not substantially change the NIOSH results.

We found little or no relation between exposure and fasting serum glucose in either data set, whether we compared the exposed to nonexposed subjects, or looked at dose-response trends. An apparent positive dose-response trend between serum glucose and TCDD in the combined group was eliminated when three outliers were deleted from the data set. The lack of a relation between serum glucose and TCDD was consistent whether the outcome we considered was either continuous serum glucose or dichotomous abnormal serum glucose $(>115 \mathrm{mg} / \mathrm{dl})$. Under the assumption that high serum glucose either defines subclinical diabetes or is a marker for increased risk of clinical diabetes, our essentially negative findings for serum glucose offer no support to the hypothesis that exposure to TCDD is related to diabetes.

Weaknesses in our data include the possibility of (a) uncontrolled confounding by unmeasured covariates, (b) selection biases, and $(c)$ possible reverse causality inherent in our cross sectional design. For confounding, we did include data on the major known risk factors for diabetes in our models, and as already noted we know of no other chemical exposures which might account for our findings. For possible selection biases, the Ranch Hand study has had good participation, arguing against such biases. ${ }^{2}$ The NIOSH study had lower participation $(70 \%$ of located workers, $28 \%$ of invited neighbourhood controls), but subsequent telephone interviews of eligible non-participants did not suggest that systematic selection biases were operating. ${ }^{3}$ Reverse causality is certainly possible in cross sectional studies in which the outcome, diabetes, is a complex hormonal disease which could affect serum concentrations of TCDD. However, if such (hypothetical) reverse causality were operating and could explain the positive dose-response in the Ranch Hand study, it would be expected that the same mechanism would cause an analogous result in the NIOSH study, which did not occur.

In summary, the epidemiological data are consistent across two cross sectional studies in showing little difference in prevalence of diabetes or fasting serum glucose between exposed and non-exposed subjects. Doseresponse trends are likewise generally absent for TCDD concentrations and serum glucose in both studies. However, the two studies are contradictory for dose-response trends for TCDD concentrations and diabetes. This analysis of the two data sets has only served to sharpen the differences in dose-response trends for diabetes which were apparent in the original publications, each of which used a somewhat different definition of outcome and a somewhat different analytical approach. When epidemiology is of necessity based on natural experiments rather than controlled clinical trials, as is the case here, it is inherently a relatively crude tool and may be subject to unknown biases or undetected effect modification. This is certainly not the first occasion when two observational studies give two 
different answers. Other studies of diabetes in populations exposed to TCDD might help resolve the difference between these two studies. Heavily exposed industrial populations in Germany and the Netherlands potentially could provide more information.

Marilyn Fingerhut, Han Kang, Marie Sweeney, Michael Stoto, and Matthew Longnecker provided thoughtful comments on the manuscript. Jim Deddens provided some statistical help.

1 Enan E, Matsumura F. TCDD-induced changes in glucose transporting activity in Guinea pigs, mice, and rats in vivo and in vitro. F Biochem Toxicol 1994;9:97-106.

2 Henriksen G, Ketchum N, Michalek J, et al. Serum dioxin and diabetes mellitus in veterans of operation ranch hand. Epidemiology 1997;8:252-8.

3 Calvert G, Sweeney M, Deddens J, et al. An evaluation of diabetes mellitus, serum glucose, and thyroid function among US workers exposed to 2,3,7,8-tetrachlorodibenzop-dioxin. Occup Environ Med 1999;56:270-6.

4 Zober A, Ott M, Messerer P. Morbidity follow-up study of BASF employees exposed to 2,3,7,8-tetradibenzo-p-dioxin (TCDD) after a 1953 chemical reactor incident. Occup Environ Med 1994;51:479-86.

5 Ott M, Zober A, Germann D. Laboratory results for selected target organs in 138 individuals occupationally selected target organs in 138 individuals occupation
exposed to TCDD. Chemosphere 1994;29:2423-37.

6 Cranmer M, Louie S, Kennedy R, et al. Exposure to 2,3,7,8-tetrachlorodibenzo-p-dioxin (TCDD) is associated with hyperinsulinemia and insulin resistance. Toxicol Sci 2000;56:431-6.

7 Steenland K, Piacitelli L, Deddens J, et al. Cancer, heart disease, and diabetes in workers exposed to $2,3,7,8$ tetrachlorodibenzo- $p$-dioxin (TCDD): an update and exposure-response analysis of the NIOSH TCDD cohort. $\mathcal{F}$ Natl Cancer Inst 1999;91:779-86.

8 Pesatori A, Zocchetti C, Guercilena S, et al. Dioxin exposure and non-malignant health effects: a mortality study. Occup Environ Med 1998;55:126-31.
9 Vena J, Boffetta P, Becher H, et al. Exposure to dioxin and non-neoplastic mortality in the expanded IARC international cohort study of phenoxy herbicide and chlorophenol production workers and sprayers. Environ Health Perspect 1998;106(suppl 2):645-53.

10 Institute of Medicine (National Academy of Science). Veterans and agent orange: update 1998. Washington, DC: National Academy Press, 1999.

11 Expert Committee on the Diagnosis and Classification of Diabetes Mellitus. Report of the Expert Committee on the diagnosis and classification of diabetes mellitus. Diabetes Care 1997;20:1183-97.

12 Patterson DG, Hampton L, Lapeza CR Jr, et al. Highresolution gas chromatographic/high-resolution mass spectrometric analysis of human serum on a whole-weight and lipid basis for 2,3,7,8-tetrachlorodibenzo-p-dioxin. Ann Chem 1987;59:2000-5.

13 SAS. SAS user's guide: statistics (version 6.07). Cary, NC: SAS Institute, 1991.

14 Buckingham Jr W. Operation ranch hand. The Air Force and herbicides in southeast Asia 1961-71. Washington, DC: Office of Air Force History, United States Air Force, 1982.

15 Institute of Medicine (National Academy of Science). Veterans and agent orange. Washington, DC: National Academy Press, 1994.

16 Lai M, Hsueh Y, Chen C, et al. Ingested inorganic arsenic and prevalence of diabetes mellitus. Am f Epidemiol 1994; 139:484-92.

17 Rahman M, Tongel M, Ahmad S, et al. Diabetes mellitus associated with arsenic exposure in Bangladesh. Am f Epidemiol 1998;148:198-203.

18 Tseng C, Tai T, Chong C, et al. Long-term arsenic exposure and incidence of non-insulin-dependent diabetes mellitus: a cohort study of arseniasis-hyperendemic villages in Taiwan. Environ Health Perspect 2000;108:847-51.

19 Agency for Toxic Substances and Disease Registry. Toxicological profile for arsenic (update). Atlanta, GA: ATSDR, 1998 .

20 Bernes C. Persistent organic pollutants, monitor 16. Stockholm: Swedish Environmental Protection Agency, 1991.

\section{Vancouver style}

All manuscripts submitted to Occup Environ Med should conform to the uniform requirements for manuscripts submitted to biomedical journals (known as the Vancouver style.)

Occup Environ Med, together with many other international biomedical journals, has agreed to accept articles prepared in accordance with the Vancouver style. The style (described in full in the $\mathcal{F} A M A[1]$ ) is intended to standardise requirements for authors, and is the same as in this issue.

References should be numbered consecutively in the order in which they are first mentioned in the text by Arabic numerals on the line in square brackets on each occasion the reference is cited (Manson[1] confirmed other reports[2][3][4][5]). In future references to papers submitted to Occup Environ Med should include: the names of all authors if there are three or less or, if there are more, the first three followed by et al; the title of journal articles or book chapters; the titles of journals abbreviated according to the style of Index Medicus; and the first and final page numbers of the article or chapter. Titles not in Index Medicus should be given in full.

Examples of common forms of references are:

1 International Committee of Medical Journal Editors. Uniform requirements for manuscripts submitted to biomed journals. ҰAMA 1993;269:2282-6.

2 Soter NA, Wasserman SI, Austen KF. Cold urticaria: release into the circulation of histmaine and eosinophil chemotactic factor of anaphylaxis during cold challenge. N Engl F Med 1976;294:687-90.

3 Weinstein L, Swartz MN. Pathogenic properties of invading micro-organisms. In: Sodeman WA Jr, Sodeman WA, eds. Pathologic physiology, mechanisms of disease. Philadelphia: W B Saunders, 1974:457-72. 